\title{
Processos de inovação e políticas de ciência e tecnologia: um olhar sobre a função social da escola brasileira na contemporaneidade
}

MÁRCIA LOPES REIS

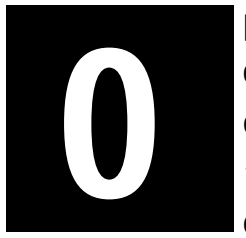

processo de absorção das novas tecnologias da informação na sociedade brasileira tem sido marcado pelo 'baixo dinamismo tecnológico', como pode ser verificado pelo 'descolamento' entre os subsistemas tecno-econômico e o marco socioinstitucional. Em recente artigo publicado, O liveira (Folha, 18/08/01) comenta sobre a condição sine qua non que se configura no contexto atual: países como Brasil e Argentina só terão chances de competir na economia do século XXI se lograrem aumentar a competitividade de forma genuína, sem depender de mudanças artificiais na taxa de câmbio, isto é, inovarem em suas práticas produtivas. Tal condição ainda segundo o autor - tem sido prejudicada pela falta de articulação entre Universidade - marco socioinstitucional - e empresa - subsistema tecno-econômico - apontando para uma parte desse quadro no qual pode-

\footnotetext{
* Doutora em Sociologia (U niversidade de Brasília), mestre em Educação (UnB) e pedagoga, professora da Universidade Católica de Brasília.
} 
se observar que - especificamente no caso do Brasil - dentre 72 países classificados de acordo com o Índice de Desempenho Tecnológico (IDT) criado pelo Programa das N ações U nidas (PNUD) e publicado no Relatório de Desenvolvimento Humano de 2001, o Brasil ocupa $043^{\circ}$ lugar, exemplifica o economista. N este artigo, pretende-se lançar um olhar sobre este descompasso desde o enfoque dado à escola - instituição aqui tomada como ambiente de inovação - responsável pelo processo de construção de práticas sociais de produção e difusão do conhecimento que contribuiriam - em última análise - para a modernização das relações sociais. Parece igualmente importante considerar que este também seria um dos objetivos das políticas de ciência e tecnologia, isto é, a mudança das práticas cotidianas, tendo como ponto de partida a introdução de novos recursos, instrumentos, técnicas, rotinas, formas de utilização do espaço e do tempo. Essas mudanças, quando analisadas desde o cotidiano das instituições, tomam o caráter de inovação, devendo constituir parte da função social da escola na contemporaneidade, que coexiste com a 'inércia institucional'evidenciada na epígrafe acima.

Desse modo, mais recentemente, parte do processo de inovação - a tecnologização ${ }^{1}$ - inerente ao quadro das práticas sociais e produtivas modernas e contemporâneas - tem provocado a reconversão de tarefas e 0 significado do trabalho humano. Decorre daí, a observação da demanda, por parte dos setores das sociedade, por mudanças também na instituição escolar. Tais demandas conviveriam lado a lado com indicadores de resistência por parte de seus atores, às mudanças, tipificando assim um quadro de inércia. Parece, no entanto, que a inércia institucional pela qual a escola pode ser caracterizada atualmente em sua prática cotidiana não é de

1 Termo inicialmente utilizado por M arcuse para quem o mundo objetivo teria sido diluído na construção de um universo tecnológico - um universo de instrumentos espirituais e materiais, pois para ele,

a própria ciência tornou-se tecnológica... Na medida em que o operacionalismo surge no centro do empreendimento científico, a racionalidade toma a forma da constituição, da organização metódica, e da manipulação da matéria como meio material de controle, como meio adequado a todas as metas e a todos os objetivos - meios per se, em si (In: DREITZEL, H.P. et allí. Tecnocracia e ideologia. Rio de Janeiro: Tempo U niversitário, 1975, p. 123). 
todo um fato novo, pois algumas inovações já foram temporariamente negadas por essa instituição. Podem ser citadas duas, sendo a primeira, a introdução do livro didático no século XVII e, a segunda, já neste século e mais próxima do caráter a ser analisado neste artigo, ocorreu após o sucesso obtido pela ex-URSS no lançamento da Sputnik, provocando reações no sistema escolar americano no sentido da utilização de recursos tecnológicos em sua prática cotidiana. Em seu tempo, a utilização de um recurso 'tecnológico' como o livro didático possibilitou uma nova organização do ensino através de currículos que foram unificados, e propostas de ensino dos governos foram possíveis, acentuando-se valores nacionalistas daquele período histórico. Quanto ao segundo exemplo, é visível o cunho tecnológico da utilização de ferramentas como televisão, rádio e computadores no âmbito institucional da escola representando, deste modo, novos elementos constituintes do projeto de uma sociedade cujos ideais de modernidade e desenvolvimento passam também pela escola².

Frente a estas contradições, quais sejam, o processo de inovação e a resistência das instituições, por vezes, evidenciadas pela inércia institucional, cabe então, inicialmente, a proposição sobre que conceito de inovação estaria sendo apropriado para as relações de $C \& T$ e a prática institucional da escola? U ma vez entendido esse conceito e a necessidade de ambientes de inovação, como podem ser pensadas as práticas educativas institucionais escolares no processo da utilização das novas tecnologias e todo o conjunto de mudanças que desencadeiam, de modo que fosse possível a caracterização da escola como um desses ambientes?

Cabe lembrar que a revisão da função social estratégica que a educação vem tomando frente às novas demandas revisita, em parte, as teorias do capital humano ou da dimensão econômica da prática educativa (Baudelot \& Establet, 1975; Carnoy, 1990; Przeworski, 1979; Schultz, 1968; entre outros) agregando-Ihes o caráter de demanda pela constituição de uma prática social inovadora. Mas, afinal, o que seria a inovação de que trata este artigo?

2 Para Fernandes (1960) a transformação do sistema de educacional de um povo em fator de desenvolvimento depende, de modo direto, da intensidade, do volume e da direção das esperanças coletivas, depositadas na educação sistemática. In: M. M. FO RACCHI e L. PEREIRA. Educação e sociedade: leituras de sociologia da educação. São Paulo: Nacional, 1969, p. 420. 


\section{Uma tentativa conceitual do processo de inovação}

Inovação pode ser definida, inicialmente, a partir do Dicionário de Ciências Sociais: qualquer pensamento, comportamento ou coisa que é nova por ser qualitativamente diferente das formas existentes (apud Barnett, 1953, p. 7). O u ainda, inovação é,

por definição, um processo aleatório, jamais realizado de antemão, adotando uma trajetória que nada tem de linear, tanto menos que a lógica das funções de uma invenção não coincide necessariamente com a lógica de seus usos: o inventor pensa que aperfeiçoou um produto ou um novo processo para este ou aquele uso, quando, na verdade, as aplicações no mercado podem ser muito diferentes(Salomon, 1991, p. 103).

Neste artigo, toma-se o conceito de inovação a partir das análises e estudo comparativo realizado por Maciel (1997), que trata de 'uma nova inovação' ao situar que, inicialmente, esse conceito se constituiu em um dos legados da O CDE como parte da resposta dos países desenvolvidos à necessidade de ações governamentais que integrassem políticas de ciência e tecnologia e políticas econômicas, portanto, viessem a diminuir 0 descompasso entre o marco socioinstitucional e o tecno-econômico - tema que perpassa qualquer revisão da função social da escola brasileira na contemporaneidade. A autora conclui sobre a necessidade de construção de um caminho próprio, cujos ambientes e atores sejam delineados a partir das práticas sociais que tipificam cada um dos países, questionando, desse modo, a adoção de modelos como única alternativa viável à implementação de práticas inovadoras: 
Hoje, diante da constatação de que essa inovação tecnológica stricto sensu não garante a competitividade e não resolve - talvez até intensifique- problemas sociais cada vez mais sérios, ligadosaos processos de produção, grande parte dos pesquisadores de inovação amplia o alcance do conceito para incluir: a organização e a gestão do trabalho na empresa, assim como formas diversificadas de educação continuada, envolvendo a qualificação e a atualização tecnológica dos trabalhadores; o desenvolvimento de formas originais nas relações entre o capital e o trabalho e na organização do trabalho nas empresas; a descentralização com integração - social, produtiva, administrativa e política; e a implantação de parques tecnológicos com vistas não só à pesquisa e à produção, mas também à formação de recursoshumanosqualificados, em colaboração com a Universidade (p. 104).

Partindo da impossibilidade de adoção de um modelo que venha assegurar a todos os países a condição de exteriorização/internalização de práticas sociais inovadoras junto aos atores/agentes, a escola passa a ser revisitada em sua função social, uma vez que se constitui em seus distintos níveis - básico e superior - como locus dotado de legitimidade para a formação de recursos humanos qualificados. No entanto, em seus efeitos de estruturação/desestruturação tais demandas por inovação em suas práticas convivem com a inércia institucional.

\section{Inovação e a inércia institucional: facetas da complexidade das práticas institucionais}

'Inércia institucional' - quando empregada por Pérez (1990) - trata das revoluções tecnológicas e transformações socioinstitucionais a partir do conjunto de hipóteses que explicam as 'ondas de Kondratieff' como sucessivos e diferentes modos de crescimento do sistema em seu conjunto. Assim, 
cada modo de crescimiento implicaría el establecimiento de un nuevo conjunto de arreglos sociales e institucionales, diseñados para favorecer el despliegue de sucesivas revoluciones tecnológicas - como se denominarán aqui sucesivos 'paradigmas tecno-científicos'(p. 421).

Pérez analisa que pode ocorrer um 'desacoplamento' entre o marco socioinstitucional e a esfera tecno-científica. A depressão seria desencadeada por este descompasso que representaria o momento de crise, em Kuhn (1979), quando comparada à definição de Pérez o fenômeno da 'inércia natural':

las instituciones, por su parte, no sólo llegan tarde en cuanto al reconocimiento de los cambios ocurridos, sino que también sufren de un alto grado de inercia 'natural', fortalecida por los éxitos del pasado y sostenida por intereses creados (p. 422).

Especificamente no caso da instituição escolar, observa-se a convivência desses dois fenômenos - inércia e inovação -, uma vez que a necessidade de enfrentar os novos padrões de produtividade e competitividade impostos pelo avanço tecnológico, vem proporcionando uma redescoberta da educação como componente essencial das estratégias de desenvolvimento. No entanto, a escola tem, em sua prática cotidiana, uma estrutura cujo funcionamento reflete as grandes desigualdades na distribuição da renda e se tem apresentado ineficiente e 'injusta' na oferta de serviços educacionais.

\section{A escola brasileira e o modelo de desenvolvimento adotado}

Em se tratando de analisar, de modo específico, o quadro da educação brasileira como estrutura socioinstitucional, cujo dinamismo seria fundamental ao cumprimento de uma agenda da modernidade, Schwartzmann (1991) também acentua os descompassos entre as novas demandas do paradigma tecno-científico e o sistema escolar brasileiro, afirmando que 
países como o Brasil ficaram, principalmente, com a carcaça das burocracias centralizadas, que foram perdendo progressivamente sua razão de ser e passaram, cada vez mais, a cuidar exclusivamente de sua própria sobrevivência. Em nenhum setor esta realidade é mais dramática, talvez, do que na área de educação básica, em que burocracias de dezenas e até centenas de milhares de pessoas desempenham suas funções de forma geralmente ritualística e rotinizada, sob o comando de administrações centraisincapazes de saber e influenciar o que ocorre onde a relação pedagógica realmente se dá, ou seja, nas sala de aula³.

Os vários indicadores educacionais permitem uma análise sobre o descompasso entre as novas demandas e as condições estruturais constituindo, desse modo, fragilidade, cujas proporções parecem ainda maiores, dado o momento de reestruturação baseada na aceleração da mudança tecnológica pelo qual a sociedade brasileira atravessa, num quadro político e econômico, local e mundial já caracterizado por sua condição volátil.

Entretanto um movimento interno contraditório pode ser verificado a partir dos índices que dão conta da rápida expansão do ensino médio, resultando na dita democratização do ensino médio, enquanto outros indicadores apontam para uma prática 'tradicional' e pouco inovadora de ensino, em que processos de desestruturação/estruturação do habitus de seus atores se opõem ${ }^{4}$. Ainda no que ser refere aos índices, observa-se, por exemplo, que menos de $30 \%$ da população na faixa etária entre 15 e 17 anos encontra-se atualmente matriculada, situando o Brasil bem abaixo dos países mais desenvolvidos nos quais mais de $80 \%$ da população nessa faixa etária freqüenta o ensino médio. Esta posição ocupada pelo Brasil é 
ainda desfavorável quando se compara a taxa de graduação deste nível de ensino em relação à população de 17 anos, idade téorica de conclusão, com os países da O ECD, ou mesmo de países da América do Sul como Argentina e Chile:

Q uadro 1: Taxa de graduação do ensino médio em relação à população de 17 anos (idade teórica de graduação)

\begin{tabular}{|l|l|l|l|}
\hline Países & Total & Homens & Mulheres \\
\hline Brasil & 32 & 20 & 46 \\
\hline Canadá & 72 & 68 & 75 \\
\hline França & 87 & 86 & 89 \\
\hline Grécia & 80 & 75 & 84 \\
\hline Itália & 67 & 64 & 70 \\
\hline Espanha & 73 & 69 & 81 \\
\hline Suécia & 64 & 60 & 68 \\
\hline Suíça & 79 & 84 & 75 \\
\hline Turquia & 37 & 43 & 31 \\
\hline M édia OECD & 80 & 80 & 85 \\
\hline
\end{tabular}

Fonte: Brasil: INEP/MEC/SEEC; países da O ECD: Education at a Giance, 1997.

Notas: $\quad$ 1. Dados do Brail se referem ao ano de 1995.

2. Dados dos países da O ECD se referem ao ano de 1994.

O síndices de acesso, que seguem baixos, constituem ao mesmo tempo, indicadores do aumento de acesso - observados no quadro 1 - permitindo evidenciar o fenômeno que Mello (1991) define como 'expansão desqualificada'. Isso porque, as ditas ações e políticas de expansão são orientadas coerentemente com os cenários políticos e econômicos observados na sociedade brasileira dessa década. Essas ações para 'democratização do acesso ao ensino médio' apresentariam, desse modo, caráter resolutivo que tipificaria o modelo de desenvolvimento adotado a partir dos seguintes fatores determinantes: 
a. o próprio modelo de desenvolvimento que se baseou na mão - de - obra desqualificada e barata, no ingresso massivo de capitais externos, na abundância de matéria prima e na formação de uma elite de tecnocratas, reduzida e sob controle, para dar sustentação ao processo de importação de tecnologia;

b. a transferência, pelo governo federal, dos custos da expansão quantitativa dos sistemas educativos para os governos estaduais e municipais, ao mesmo tempo em que havia um processo de concentração tributária no âmbito federal,

c. uma forte, extremamente complexa e contraditória associação de interesses corporativos dentro do aparato do Estado, envolvendo: as empresas prestadoras de serviços de construções escolares; a classe política e sua clientela, que sempre pressiona no sentido de obter a sua escola; a classe média, que teve acesso à formação superior privada, buscou, em sua maioria, os cursos de formação de professores e ingressou no mercado pressionando por postos de emprego no sistema de ensino público; os setores do ensino privado, que tiveram nos futuros profissionais da escola pública seus clientes cativos (p. 48)

Esses fatores, quando relacionados às políticas de modernização do ensino médio - por exemplo -, a partir da adoção dos recursos das NTIs, fazem rever também uma 'política de resultados' (Bosi, 1992) que vem orientando a prática governamental ao longo dessa década. As análises do movimento interno contraditório para caracterização da inércia institucional do sistema de ensino brasileiro - aqui observadas a partir do nível médio de ensino - prosseguem, uma vez consideradas as relações entre os indicadores tradicionais de avaliação de seu funcionamento - matrícula,

5 MELLO, G. N. e SILVA, R. N. A gestão e a autonomia da escola nas novas propostas de políticas educativas para a América Latina. In: Estudos Avançados, 12 (5), 1991, pp. 45-61. 
repetência, evasão, sobretudo - e indicadores 'não - tradicionais' como aqueles que apontam sua eficiência. Assim, se do ponto de vista da expansão da matrícula, o ensino médio alcançou um desempenho expressivo na década de 90, o mesmo não pode ser afirmado em relação aos indicadores que dizem respeito à adequação de conteúdos, normas, recursos à população que representa a clientela deste nível de ensino no Brasil e nos quais seria possível mensurar o impacto na formação de recursos humanos com caráter de inovação. Em se mantendo as incoerências estruturais, as próprias taxas de transição tendem a um aumento das taxas de repetência e lenta diminuição dos índices de evasão:

Q uadro 2: Taxas agregadas de transição no ensino médio do Brasil (1981 -2010)

\begin{tabular}{|l|l|l|l|}
\hline Ano & $\begin{array}{l}\text { Promoção } \\
(\%)\end{array}$ & $\begin{array}{l}\text { Repetência } \\
(\%)\end{array}$ & $\begin{array}{l}\text { Evasão } \\
(\%)\end{array}$ \\
\hline 1981 & 67 & 25 & 8 \\
\hline 1985 & 60 & 31 & 9 \\
\hline 1990 & 60 & 32 & 8 \\
\hline 1995 & 61 & 34 & 5 \\
\hline 1998 & 60 & 36 & 4 \\
\hline $2000^{*}$ & 59 & 37 & 4 \\
\hline $2002^{*}$ & 59 & 38 & 4 \\
\hline $2004^{*}$ & 58 & 39 & 4 \\
\hline $2005^{*}$ & 57 & 39 & 3 \\
\hline $2008^{*}$ & 56 & 41 & 3 \\
\hline $2010^{*}$ & 55 & 42 & 3 \\
\hline
\end{tabular}

Fonte: MEC/INEP/SEEC, 1999.

(*) Dados estimados.

0 atendimento a uma clientela cada vez mais heterogênea e o fato de que o sistema educacional não tem agregado novos 'fatores-chave' constituem parte das relações explicativas para o fenômeno da inércia institucional 
do ensino médio brasileiro. Toma-se como exemplo o fato de que, em novembro de 1997, o Instituto Nacional de Estudose Pesquisas Educacionais INEP - divulgou os principais resultados de uma pesquisa realizada junto a 430 mil concluintes do ensino médio, cujo objetivo seria caracterizar a heterogeneidade desses alunos. U m dos aspectos considerados relevantes, trata da renda mensal, um dos fatores que possibilita a definição dos níveis socioeconômicos. Constatou-se que $53 \%$ dos alunos que conseguem completar os 11 anos de educação básica fazem parte de uma camada da população brasileira com renda inferior a seis salários mínimos - $\mathrm{R} \$ 720,00$. 0 bservou-se, também, uma concentração de alunos das faixas de renda mais altas - acima de R\$1.201,00 - nos cursos acadêmicos diurnos (36.4\%) enquanto $66 \%$ dos alunos de cursos profissionalizantes noturnos têm renda familiar até $\mathrm{R} \$ 720,00$. A diferenciação entre turnos diurno e noturno aparece em todos os Estados pesquisados, em maior ou menor grau. Nos Estados da Bahia, Pernambuco e Rio Grande do Norte, mais da metade dos concluintes do ensino médio pertence a famílias cuja renda mensal é inferior a R\$360,00. Nos Estados de Goiás, Paraná, Rio de Janeiro e Rondônia, 0 número de alunos com o mesmo nível de renda familiar cai para cerca de um terço do total. Em São Paulo, apenas 15\% dos alunos encontram-se nesta faixa de renda, em razão do maior poder aquisitivo da população. Em relação à idade, novamente vale que a expectativa é de que o aluno conclua o ensino médio quando estiver completando 17 ou 18 anos. No entanto, entre os alunos de ensino médio do Brasil, mais da metade dos concluintes - 50,36\% - apresenta o fenômeno da distorção série/idade, sendo expressivo o percentual de alunos com mais de 21 anos - 25,24\%. Este aspecto aproxima o ensino médio do quadro verificado junto ao ensino fundamental, enquanto as diferenciações entre as características socioeconômicas desta modalidade de ensino o aproximam do ensino superior no Brasil. As avaliações demonstraram ainda que o desempenho dos alunos varia negativamente conforme aumenta a distorção série/idade. 
Em relação à escolaridade dos pais, evidencia-se um quadro de significativa mobilidade educacional - ainda que não exerça impactos sobre a mobilidade social: no grupo de alunos que estava concluindo o ensino médio em 1997, apenas 9,02\% dos pais e 7,19 das mães possuíam nível de escolaridade superior ao alcançado pelos filhos. Por outro lado, cerca de $50 \%$ dos jovens são filhos de pais que não completaram o ensino fundamental - antigo $1^{\circ}$ grau -, cerca de $11 \%$ dos pais possuem o ensino médio de escolaridade e apenas $5 \%$ possuem o nível superior completo. 0 quadro heterogêneo também pode ser evidenciado quando se relaciona à questão do emprego: a maioria conciliou trabalho com estudo durante 0 curso (60\%), proporção que chega a $72 \%$ entre os alunos do turno noturno. A pesquisa indicou ainda que $19,26 \%$ dos alunos do turno noturno começaram a exercer atividade remunerada antes dos 14 anos de idade e $34,47 \%$ entre os 14 e 16 anos, proporção que diminui para $16,26 \%$ no turno diurno. Ainda relacionado com a questão do trabalho, observou-se que $13 \%$ dos alunos declararam estar desempregados, percentual que se eleva para $31,7 \%$ no turno noturno profissionalizante.

As expectativas dos concluintes do ensino médio também são bastante diversificadas: para $31,5 \%$ dos alunos, a principal expectativa era a continuidade de seus estudos, prosseguindo para o ensino superior. A outra acentuada expectativa gerada pelo ensino médio continua estando relacionada ao trabalho, pois, com exceção dos alunos dos cursos acadêmicos diurnos, os demais analisam a escola secundária como instrumento que lhes possibilita o ingresso ou a melhoria de sua posição no mercado de trabalho. De fato, para $20,5 \%$, a expectativa ao concluir o ensino médio seria a melhor qualificação para o mercado de trabalho, e para outros $13 \%$, o caminho para obter o emprego.

0 conjunto de fatores que diferenciam e tornam o ensino médio heterogêneo em suas especificidades deve ser considerado nas análises sobre o fenômeno da 'inércia institucional', na medida em que, a incoe- 
rência estrutural verificada em relação ao âmbito das condições técnicas e econômicas é igualmente verificada no próprio funcionamento da instituição escolar de nível médio. As reformas quase decenais pelas quais a educação brasileira vem passando desde a criação do Ministério da Educação e da Saúde, na década de 30, deixam transparecer que os elementos constituintes do conceito de 'escola', independentemente do nível de escolaridade a que se propõe, vem-se modificando muito lentamente face às demandas sociais e econômicas, internas e externas, de um país periférico. Em se tratando especificamente do ensino médio, as modificações no que se refere às metodologias, técnicas de ensino e recursos empregados demandam um redimensionamento que venha a caracterizar um outro etnométodo coerente entre as condições técnico-econômicas e o habitus da prática cotidiana dos atores desta instituição social.

\section{À guisa de conclusão}

Neste artigo, procurou-se evidenciar que a reformulação do sistema de ensino em suas práticas cotidianas é hoje uma tendência mundial, cuja preocupação tem sido aproximar cada vez mais as instituições escolares em seus distintos níveis - e os setores produtivos da sociedade. Para tanto, dotar tais práticas de inovação inserindo recursos decorrentes do processo de tecnologização das relações de produção tem sido uma demanda que requer desses atores e agentes o sentido da inovação. 0 dilema que se configurava entre a preparação para o exercício da cidadania e o ingresso no mercado de trabalho parece imbuído, em suas distintas facetas, pelo ethos da inovação que o caracteriza como processo socialmente estruturado: a escola contemporânea deve ser, acima de tudo, preparação para a vida num mundo em constante mudança, contexto no qual deve colocar em relevância a capacidade de entender o que ocorre ao redor de si e propor soluções inovadoras e não, a aquisição de uma habilidade técnica qualquer que se 
torna obsoleta em períodos cada vez menores. Há que se considerar a necessidade de constituição das práticas escolares como um ambiente de inovação - dotado de seus efeitos de afirmação/negação, uma vez que a própria tecnologização apresenta em seus efeitos a condição de estruturação/ desestruturação: a atividade tecnológica é vista por um lado, como fator constitutivo da vida do homem em sociedade e, por outro, a tecnologia implica escolhas e decisões tanto para sua produção, como para sua difusão e consumo, delineados a partir de um movimento interno contraditório. Neste movimento, observável nas instituições escolares nas quais ocorre a utilização destes recursos, nota-se a resistência verificada no desempenho das tarefas, por parte de alguns atores da escola, frente às tendências das novas tecnologias, cujo caráter parece irreversível e cada vez mais abrangente. Por outra parte, observa-se uma absorção pouco refletida eliminando os sujeitos pela preponderância arrasadora da lógica dosmeios.

Sem o determinismo tecnológico - que poderia caracterizar toda e qualquer implementação de uma prática inovadora, a escola continuaria marcada pelos condicionantes socioeconômicos, da origem rural e, sobretudo, da renda familiar percebida, embora essas discriminações sejam mediatizadas pelos níveis de desenvolvimento regional e local, cujas conjunturas reforçam ou atenuam as diferenças entre classes e grupos sociais. U ma outra dimensão analítica correlata ressaltou a importância da revisão das práticas que poderia ressaltar a defasagem e o desnível dos perfis de escolaridade do Brasil em face de outros países latino-americanos. Tornase evidente, desse modo, o provável fosso a ser enfrentado pelo país no processo de modernização acelerada e de transformação científica e tecnológica, neste início de século, cuja principal tarefa talvez seja atualizar a agenda da modernidade, erradicando todas as formas de analfabetismo que subsistem desde o século XI, bem como a implementação de práticas inovadoras no âmbito das relações sociais cotidianas da escola em todos os seus níveis e modalidades. 


\section{Referências bibliográficas}

BENAKO UCHE, R. M imetismo tecnológico. Florianópolis: UFSC, 1984.

A questão da informática no Brasil. São Paulo: Brasiliense/CNPq, 1985.

CARN OY, M. Educação, economia e Estado - base e superestrutura relações e mediações. São Paulo: Cortez, 1990.

CASTELLS, M. Mudança tecnológica, reestruturação econômica e a novas Divisão Internacional do Trabalho. In: Revista Sociedade e Território, n³. Porto, 1985.

CATALÃ, V. Zeus: informática y video - educación y nuevas tecnologías. Madrid: Grupo Logo, 1986.

CHALK, R. Science, technology and society: emerging relationships. W ashington D. C.: American Association for the Advancement of Science, 1988.

COMBS, P. H. A crise mundial da educação. São Paulo: Perspectiva, 1976.

DINIZ, E. (org.) O Brasil no rastro da crise; partidos, sindicatos, movimentos sociais, Estado e cidadania no curso dos anos 90. São Paulo: ANPO CS/HU CITEC/IPEA, 1994.

ELLUL, J. El siglo XX y la técnica. Barcelona: Labor, 1954.

ELSTER, J. El cambio tecnológico. Barcelona: Gedisa,1990.

FERN ANDES, A. M. (org.) Colapso da ciência e tecnologia no Brasil. Rio de Janeiro: Relume-Dumará, 1994.

FIGUEIREDO, V. Produção social da tecnologia. São Paulo: EPU, 1989.

FREEMAN, C. y SOETE, L. N ew explorations in the economics of technical change. London, Frances Pinter, 1990.

FREITAG, B. Política social e educação. In: Em aberto. Brasília, INEP, 1985, 27.

FRIJH O FF, W. L'Etat et l'éducation (XVIe - XVII) e siècle: une perspective globale. In: Culture et idéologie dans la genèse de l'Etat moderne. Actes de la table ronde organisée par le Centre National de la Recherche Scientifique et l'École Française de Rome. École Française de Rome, 1985. 
FUNDAÇÃO GETÚLIO VARGAS. Dicionário de Ciências Sociais. Instituto de Documentação; Benedito Silva, coordenação geral; Antonio Garcia de Miranda Netto.../ et allí/ 2ạ ed. Rio de Janeiro: Fundação Getúlio Vargas, 1987.

GODELIER, M. Economía, fetichismo y religión en las sociedades primitivas. Buenos Aires, 1974.

H ABERM AS, J. Técnica e ciência enquanto "ideologia". Textos escolhidos/ (...) Jürgen Habermas. São Paulo: Abril Cultural, 1980.

HARVEY, D. Condição pós-moderna. São Paulo: Loyola, 1992.

H O BSBAW N, E. Era dos extremos: o breve Século XX 1914 / 1991.São Paulo: Companhia das Letras, 1995.

IRANZO, J. M. et allí. Sociología de la ciencia y la tecnología. M adrid: CSIC, 1995.

JASAN O FF, S. et allí. Handbook of science and technology studies. Londres: Sage, 1995.

KRANZBERG, M. y DAVENPORT, W. Tecnología y cultura. Barcelona: Gustavo Gili, 1978.

LÉVY, P. As tecnologias da inteligência: o futuro do pensamento na era da informática. Rio de Janeiro: Ed. 34, 1993.

LEITE, E. M. Reestruturação produtiva, trabalho e qualificação no Brasil. In: BRUNO, L. Educação e trabalho no capitalismo contemporâneo. São Paulo: Atlas, 1996.

M ACIEL, M. L. Inovação e conhecimento. In: SO BRAL, F. et all. (orgs.) A alavanca de Arquimedes - ciência e tecnologia na virada do século. Braślia: Paralelo 15, 1997.

MITCHAM, C. Thinking through technology: the path between engineering and philosophy. Chicago: University of Chicago Press, 1994.

NEGRO PO NTE, N. A vida digital. São Paulo: Companhia das Letras, 1995.

NOBLE, D. El diseño de los Estados Unidos: la ciencia, la tecnología y la aparición del capitalismo monopolístico. Madrid: Ministerio de Trabajo y Seguridad Social, 1987. 
NUNES, B.F. Sistema e atores da ciência e tecnologia no Brasil. In: A. M. FERNANDES e F. A. SO BRAL (orgs.) Colapso da Ciência \& Tecnologia no Brasil. Rio de Janeiro: Relume - Dumará, 1994. pp. 41 - 79.

. Estado, ciência e tecnologia no Brasil: uma análise retrospectiva. In: Revista Sociedade e Estado, vol. V, n², jul. / dez., 1990.

PACEY, A. El laberinto del ingenio. Barcelona: Gustavo Gili, 1980. . La cultura de la tecnología. M éxico: FCE, 1990.

PAIVA, V. Inovação tecnológica e qualificação. In: Revista Educação \& Sociedade, Campinas: Papirus, ano XVI, abril, 1995.

. O novo paradigma de desenvolvimento: educação, cidadania e trabalho. In: Revista Educação \& Sociedade, Campinas: Papirus, ano XIV, agosto, 1993.

PORTO, M. S. G. A tecnologia como forma de violência. In: Revista Sociedade e Estado, vol. VII, n 1-2, jan./dez.1992. pp. 79 - 97.

PEREZ, C. Revoluciones tecnológicas y transformaciones socio-institucionales. In: CRAGNOLINI, A. (ed.) Cuestiones de política científica y tecnológica. Consejo Superior de Investigaciones Científicas, Madrid, s/d.

POSTMAN, N. Tecnopólio. Trad. Reinaldo Guarany. São Paulo: Nobel, 1994.

PRZEW O RSKI, A. Economic conditions of class compromise. University of Chicago, 1979, mimeo.

PRICE, R. F. M arx and education in late capitalism. Surry Hills, Croom Helm, 1986. RO SEN BERG, N. Tecnología y economía. Barcelona: Gustavo Gili, 1979.

. Dentro de la caja negra: tecnología y economía. Barcelona: La Llar del Llibre, 1993.

SALOMON, J. J. History and technology. Vol.I. London: Harwood Academic Publishers GmbH, 1984. 
SCH M ITZ, H. Automação microeletrônica e trabalho: a experiência internacional. In: SCH M ITZ, H. e CARVALH O, R. de C. Automação, competitividade e trabalho: experiência internacional. São Paulo: HUCITEC, 1988.

SCHW ARTZM ANN, S. Educação básica no Brasil: a agenda da modernidade. In: Estudos Avançados - USP. São Paulo: Instituto de Estudos Avançados, vol 5, $n^{\circ} 13$, jan/abril, 1991, p. 52 - 53.

SO BRAL, F. A. F. Educação e mudança social: uma tentativa de crítica. Braślia: UnB/Instituto de Ciências Humanas, Departamento de Ciências Sociais, Brasília, 1976 (Dissertação de Mestrado).

TURKLE, S. Life on the screen - identity in the age of the Internet. N ew York: Simon \& Shuster, 1995.

WATKINS, P. Technology, the economy and education. Victoria, Deakin University, 1985.

WATSON, D. M. The impact report: na evaluation of trh impact of information technology on children-ses achievements in primary and secondary schools. London: King's College, 1993. 